Jpn. J. Genet. (1989) 64, pp. 383-389

\title{
Migration and linkage disequilibrium in local populations of the housefly (Musca domestica) in Japan
}

\author{
Takashi Tomita and Yoshito WADA* \\ Department of Medical Entomology, National Institute of Health \\ Kamiohasaki 2-10-35, Shinagawa-ku, Tokyo 141
}

(Received 21 August 1989)

\begin{abstract}
Housefly populations in Hokkaido, Japan were examined. The frequency of females carrying a female-determining factor $\left(F^{\prime}\right)$, which is epistatic to the male-determining factor $(M)$, has been estimated to be very low. This means that most of the chromosomes carrying an $M$ factor are transferred from male parents to their male progeny without recombination. Based on this characteristic situation, the association between the $M$ factor and one of the $6 P G D$ alleles in Hokkaido in 1983 and 1984 was studied, and strong linkage disequilibrium was found in the samples from six spots in and around Sapporo. A specific allele, $6 P G D^{I}$, was associated in most of the cases with the $M$ factor-carrying third chromosome (III ${ }^{\mathrm{M}}$ ). The $6 P G D$ locus was highly polymorphic in the $M$ factorfree third chromosome (III). Based on these experimental results, it is suggested that the frequency of chromosome III $^{\mathrm{M}}$ has recently increased in the population around Sapporo.
\end{abstract}

\section{INTRODUCTION}

In the housefly, Musca domestica, a necessary condition for maleness in an individual is the presence of a male-determining factor, $M$ (Hiroyoshi, 1964; Rubini and Palenzona, 1967). Although the $Y$ chromosome is basically an $M$ factor-carrier, $M$ factors have been demonstrated in all of the five autosomal linkage groups (Sullivan, 1958; Wagoner, 1969; Hiroyoshi and Inoue, 1979; Inoue et al., 1986). Moreover, natural populations which are hard to detect the $Y$ chromosome have been found in the United States (McDonald et al., 1975), Italy (Franco et al., 1982) and Japan (Tsukamoto et al., 1980). It is postulated that the frequency of $M$ factor-carrying autosomes $\left(\mathrm{A}^{\mathrm{M}}\right)$ has increased in natural populations (in Japan, Hiroyoshi and Fukumori, 1977; Tomita and Wada, 1989; in Italy, Franco et al., 1982) in the past few decades. There are, however, some difficulties in establishing this postulated phenomenon, due to the limited number of direct comparisons in natural populations.

The present study provides the experimental evidence for the above phe-

* Present address: Department of Medical Entomology, Institute of Tropical Medicine, Nagasaki University, Sakamoto-machi 12-4, Nagasaki 852 
nomenon, using linkage disequilibria between some isozyme marker genes and the $M$ factor. In the populations of Hokkaido examined so far, the $F$ factor, which makes a carrier of $M$ develop into a fertile female, is very rare (Shono et al., 1982; Tomita and Wada, 1989). On the other hand, the frequency of chromosome $\mathrm{III}^{\mathrm{M}}$, which is the most predominant $A^{\mathrm{M}}$ in Japan (Hiroyoshi and Fukumori, 1977; Tomita and Wada, 1989), is high. Therefore, a chromosome III $^{\mathrm{M}}$ in these populations must be transferred from a male parent to his male progeny, and then act as a super-gene complex, since recombination is rare in the male. If the frequency of $\mathrm{III}^{\mathrm{M}}$ increased recently from a few founder chromosomes in natural populations, one of its genetic consequences in the $F$ factor-free populations is the existence of linkage disequilibrium between the $M$ facotr and its neighboring genes in the third chromosome. On the basis of this finding, we are able to speculate about the timing of the invasion of the III $^{\mathrm{M}}$ chromosome.

\section{MATERIALS AND METHODS}

Flies were collected at the following 9 spots in 4 areas stretching from west to east in Hokkaido in 1983 and 1984; 6 spots were within a circle of $11 \mathrm{~km}$ radius in or near Sapporo, and 1 spot each in Furano, Obihiro and Akkeshi (Fig. 1).

The method of determining the presence or the absence of the $F$ factor in females was described in the accompanying paper (Tomita and Wada, 1989).

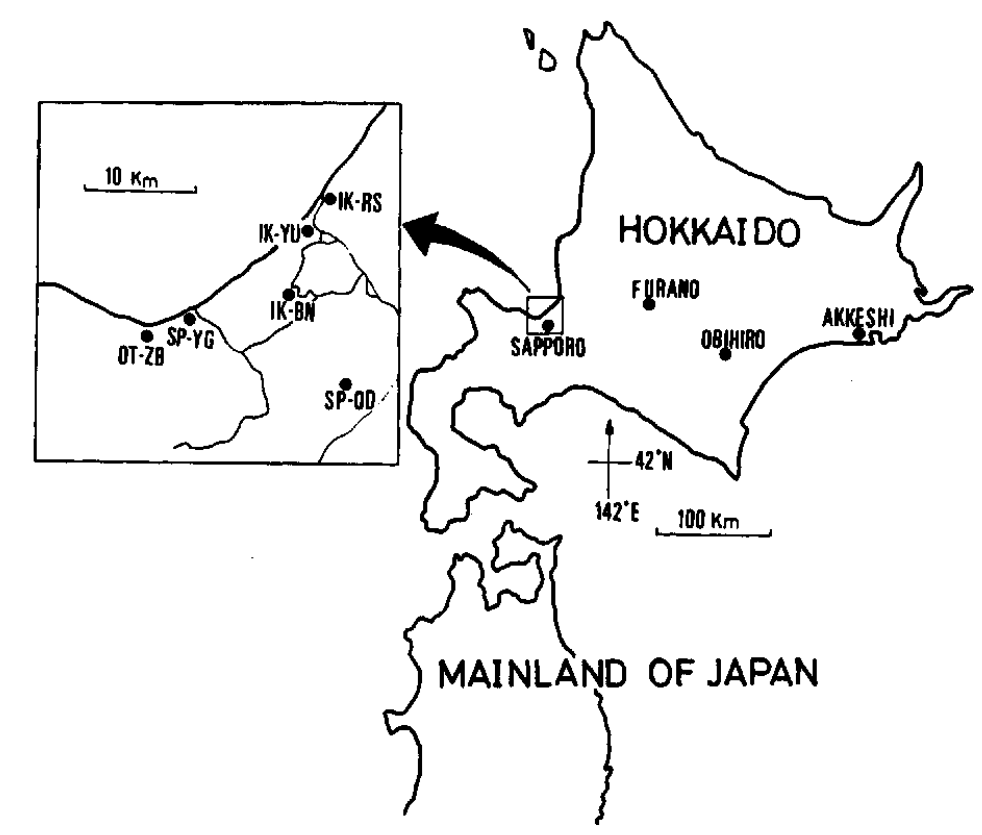

Fig. 1. Geographic locations of the 9 collection spots in Hokkaido, Japan. 
Linkage relationships of the $M$ factor were determined directly in the males sampled from wild populations, using the $a c ; a r ; b w b ; y e ; s n p$ mating method (Tomita and Hiroyoshi, in preparation). In this process, the $F_{1}$ offspring obtained from single male matings with the mutant females were used for the test of the 6-phosphogluconate dehydrogenase (6PGD) genes on the third chromosome. The electromorphs were tested by starch gel electrophoresis (Stone et al., 1968). If a parental male contained chromosome III $^{\mathrm{M}}$ heterozygously, the $6 P G D$ gene on this chromosome was tested in the male progeny. If it contained no III $^{\mathrm{M}}$, the gene on either of the homologous chromosome IIIs was tested.

The female recombination values among the $w, b w b$ and $p w$ loci were estimated for the chromosome IIIs and III ${ }^{\mathrm{M}_{\mathrm{S}}}$ extracted from the Sapporo sample in 1985, in the same way as genes on chromosome $\mathrm{III}^{\mathrm{M}}$ were mapped by Inoue and Hiroyoshi (1984), using the marker strain, $M k \mathrm{II}^{\mathrm{M}} ; w b w b p w ; B a F$.

\section{RESULTS AND DISCUSSION}

The genotypes controlling sex determination and the electromorph of the $6 P G D$ genes on the third chromosome were surveyed in each of the 9 spots in 4 areas in Hokkaido in 1983 and 1984. The results are summarized in Table 1. The upper 3 rows show the results obtained from Furano, Obihiro and Akkeshi, 1983. The lower 7 rows show those from spots in and around Sapporo, 1983 and 1984.

The $F$ factor is sporadically distributed in populations of Japan (Tomita and

Table 1. The frequencies of genotypes and haplotypes for the sex-determining and $6 P G D$ genes

\begin{tabular}{|c|c|c|c|c|c|c|c|c|c|c|}
\hline \multirow[b]{2}{*}{ Sample } & \multicolumn{2}{|c|}{ Female } & \multicolumn{3}{|c|}{ Male } & \multicolumn{2}{|c|}{ Chr. III } & \multicolumn{2}{|c|}{ Chr. III ${ }^{\mathrm{M}}$} & \multirow[b]{2}{*}{$\chi^{2 \#}$} \\
\hline & $\underset{\text { size }}{\text { Sample }}$ & $F /+$ & $\begin{array}{c}\text { Sample } \\
\text { size }\end{array}$ & $\begin{array}{c}\text { Plural } \\
M \\
\text { factor- } \\
\text { carrying }\end{array}$ & $\begin{array}{l}\mathrm{Chr}_{-} \\
\text {carrying }\end{array}$ & $\underset{\text { size }}{\text { Sample }}$ & ${ }_{6} P G D^{I}$ & $\begin{array}{c}\text { Sample } \\
\text { size }\end{array}$ & $6 P G D^{I}$ & \\
\hline FR 83 & 6 & 0 & 83 & 0 & 0.08 & 76 & 0.45 & 7 & 0.86 & $*$ \\
\hline OH 83 & 9 & 0 & 38 & 0 & 0.21 & 30 & 0.47 & 8 & 0.50 & NS \\
\hline AK 83 & 28 & 0 & 61 & 0 & 0.21 & 48 & 0.33 & 13 & 0.46 & NS \\
\hline SP-YG 83 & 23 & 0 & 124 & 0 & 0.40 & 75 & 0.37 & 49 & 0.98 & $* *$ \\
\hline SP-YG 84 & 30 & 0 & 49 & 0 & 0.24 & 37 & 0.54 & 12 & 1.0 & $* *$ \\
\hline SP-OD 84 & 31 & 0 & 52 & 0 & 0.33 & 35 & 0.49 & 17 & 1.0 & $* *$ \\
\hline IK-RS 84 & 30 & 0.03 & 51 & 0.02 & 0.24 & 38 & 0.45 & 12 & 1.0 & $* *$ \\
\hline IK-YU 84 & 26 & 0 & 50 & 0 & 0.30 & 35 & 0.57 & 15 & 0.93 & $* *$ \\
\hline IK-BN 84 & 28 & 0 & 46 & 0 & 0.35 & 30 & 0.50 & 16 & 1.0 & $* *$ \\
\hline OT-ZB 84 & 27 & 0 & 55 & 0 & 0.29 & 39 & 0.41 & 15 & 1.0 & $* *$ \\
\hline
\end{tabular}

\# Linkage disequilibrium between $6 P G D$ genes and $M$ factors in the ihird chromosomes.

* Significant at the $5 \%$ level.

** Significant at the $1 \%$ level. 
Wada, 1989), but the frequencies in the Hokkaido populations are estimated to be very low. This is directly shown from the results of the female test or indirectly suggested by the fact that the males containing plural $M$ factors were rare (Table 1). Chromosome III $^{\mathrm{M}}$ is now widely distributed in Japanese populations (Tomita and Wada, 1989), and it was the second most frequent class of $M$ factor-carriers among 6 pairs of the chromosomes in Hokkaido populations, following the $Y$ chromosome (Tomita and Wada, 1989). These results ensure the holandric inheritance of chromosome III $^{\mathrm{M}}$ in natural populations, which is a necessary condition for the present study.

There are at least three alleles at the $6 P G D$ locus, $6 P G D^{I}, 6 P G D^{S}$, and $6 P G D^{F}$. Only the frequencies of the predominant allele, $6 P G D^{I}$, are shown in Table 1. The $6 P G D$ locus on chromosome III was highly polymorphic in every sample. The frequencies of $6 P G D^{I}$ ranged from 0.33 in the Akkeshi sample to about 0.5 in each of the samples from Sapporo and its suburbs. In contrast, the frequencies of the $6 P G D$ in chromosome $\mathrm{III}^{\mathrm{M}}$ were markedly different among the areas. In the seven samples from 6 spots in and around Sapporo, the 6PGD locus on chromosome III ${ }^{\mathrm{M}}$ was consistently monomorphic or nearly so for the $6 P G D^{I}$ allele. However, in each of the Obihiro and Akkeshi samples, the locus was highly polymorphic. Linkage disequilibrium (or non random association) between the $6 P G D$ alleles and $M$ factors in the third chromosome was tested by the $\chi^{2}$ method with the frequencies pooled for $6 P G D^{F}$ and $6 P G D^{S}$ (Table 1). The $\chi^{2}$ for each of the 7 samples of Sapporo and its suburbs was significant at the $1 \%$ level and that of Furono was significant at the 5\% level. However, the values of Obihiro and Akkeshi were not significant. Both from the significant linkage disequilibria and from the homogenous values in each of the frequencies in the 5 columns $(F /+$ female, male carrying plural $M$ factors, male carrying chromosome $\mathrm{III}^{\mathrm{M}}$, and the chromosomes III and III ${ }^{\mathrm{M}}$ associated with $6 P G D^{I}$ allele) in the samples from Sapporo and its suburbs, the specific association of the $6 P G D^{I}$ allele with the chromosome $\mathrm{III}^{\mathrm{M}}$ is inferred to be generally present in the natural population in and around Sapporo.

The time since the immigration of chromosome $\mathrm{III}^{\mathrm{M}}$ to the Sapporo area can be estimated by the application of Nei and Li's (1980) equation,

$$
d_{n} \cong \mathrm{d}_{0}(1-c)^{n}
$$

where $c$ is the recombination value between the $6 P G D$ gene and the $M$ factor in males, and $d_{0}$ (or $d_{n}$ ) is the difference between the $6 P G D^{I}$ allele frequencies in chromosomes III ${ }^{\mathrm{M}}$ and III at generation 0 (or $n$ ). This formula assumes the constancy of the $6 P G D$ allele frequencies in chromosome III, which is reasonable in this study. Because the male recombination value, $c$, was not estimated directly, it was obtained as a product of $k c^{\prime}$, where $k$ is the ratio of male to female recombination value and $c^{\prime}$ is the female recombination value.

Before proceeding to the above estimation, some considerations of chromosomal 
polymorphisms that might exist in the natural population of the houseflu should be made. At least three types of III $^{\mathrm{M}}$ chromosome maps have been demonstrated by Inoue and Hiroyoshi (1984) in several strains from Japan and elewhere on the basis of meiotic recombination in $F$ factor-carrying females. The three types of maps are identical in the order of the loci (the order is $w b w b p w M$, from distal to proximal), but markedly different in the distances between neighboring loci, except for the $p w-M$ interval. On the maps of types 1,2 and 3 , the distances between $w$ and $b w b$ are 15-22, 35-36 and 0.3, respectively, and the distances between $b w b$ and $p w$ are 41-47, 4-6 and 3, respectively (Inoue and Hiroyoshi, 1984); these differences may be due to chromosomal rearrangement. In this study, the type of gene arrangement in chromosome IIIs and III ${ }^{\mathrm{M}} \mathrm{S}$ of the Sapporo population was determined by recombination tests, following the same procedure as described in Inoue and Hiroyoshi (1984).

Table 2 shows the recombination frequencies among the $w, b w b$ and $p w$ loci in the $F /+$ females, which were made heterozygous with the chromosome III or III $^{\mathrm{M}}$ extracted from the 1985 fly sample in one of the sites of earlier sampling in Sapporo (denoted by SP-YG in Table 1). The per cent recombination frequencies between the $w$ and $b w b$ loci and between the $b w b$ and $p w$ loci were within the intervals of $15-22$ and $43-49$, respectively. The results indicate that the gene arrangements along all the third chromosomes tested correspond quite well with the type 1 map in Inoue and Hiroyoshi (1984) and the standard linkage map in Hiroyoshi (1977). Therefore, assuming monomorphism for the type 1 third chromosome of the housefly in the Sapporo population, the following estimation was made on hte basis of recombination in the homokaryotype of the type 1 third chromosome.

Table 2. Female recombination frequencies along the third chromosomes extracted from the Sapporo sample (SP-YG 85)

\begin{tabular}{cccc}
\hline Third & $\begin{array}{c}\text { Thromosomes } \\
\text { tested }\end{array}$ & $\begin{array}{c}\text { No. of } \\
\text { chromosomes } \\
\text { extracted }\end{array}$ & \multicolumn{2}{c}{ Recombination frequencies (\%) } \\
\cline { 3 - 4 } & 23 & $w-b w b$ & $b w b-p w$ \\
\hline III & 8 & $16-22$ & $43-49$ \\
III $^{\mathrm{M}}$ & & $15-21$ & $46-49$ \\
\hline
\end{tabular}

On the type 1 map, the distances between $b w b$ and $p w$ loci and between $p w$ and $M$ loci are 44.6 and $0.1 \mathrm{cM}$., respectively (averaged from Inoue et al., 1983 and Inoue and Hiroyoshi, 1984), and the distance between $b w b$ and $g e$ loci is $25.8 \mathrm{cM}$. (Hiroyoshi, 1977), where the ge locus is located proximal to the $b w b$ locus and is whithin one map unit of the $6 P G D$ locus (Malacrida et al., 1982). Thus, the value of $c^{\prime}$ was estimated to be $(44.6-25.8+0.1) \times 10^{-2}=18.9 \times 10^{-2}$. The rate of male to female recombination frequency, $k$, is estimated to be 0.013 for the region of 
$w$-bwb-pw (Inoue et al., 1983). Using the combined data for the samples from Sapporo and its suburbs in 1984 (Table 1), $d_{0}$ and $d_{n}$ were estimated to be 0.51 and 0.50 , respectively.

Thus, the value of $n$ can be estimated by the above equation to be 8, assuming that the third chromosomes employed were type 1. This estimated generation number leads to the simple conclusion that the number of generations since immigration of chromosome III $^{\mathrm{M}}$ into the Sapporo population is extremely small.

The most reasonable interpretation of the linkage disequilibrium found in the natural populations in and around Sapporo is that chromosome III $^{\mathrm{M}}$ was monomorphic for the $6 P G D^{I}$ allele when some number of these chromosome were introduced into the population, that the frequency of chromosome III $^{\mathrm{M}}$ increased by unknown mechanism and that the linkage disequilibrium has been retained due to the rarity of recombination events. Green (1980) suggested that the various linkage relationships of the $M$ factors found in several dipteran species including the housefly are caused by transposition of these factors. If the transposition of the $M$ factor, such as from $Y$ to the third chromosome, had been recurrent and the frequency of chromosome $\mathrm{III}^{\mathrm{M}}$ had increased, isozyme polymorphisms on chromosome III $^{\mathrm{M}}$ should have been detected in present natural populations, especially in populations with a high frequency of chromosome $\mathrm{III}^{\mathrm{M}}$, such as the Sapporo population. Contrary to the above expectation, the chromosome $\mathrm{III}^{\mathrm{M}}$ population was monomorphic. Therefore, the $M$ factor seems to be stable in the third chromosome in the natural population of Sapporo. In the samples from Obihiro and Akkeshi, the $6 P G D$ locus on chromosome III $^{\mathrm{M}}$ was polymorphic, as in chromosome III. These results might be due to the input of polymorphic III $^{\mathrm{M}}$ chromosomes into the populations. If the $F$ factor exists in natural populations at a high frequency, linkage disequilibria between the $M$ factors and the alleles at the other loci on the same chromosomes would gradually disappear by recombination, since the $F$ factor is epistatic to the $M$ factor. This may be the actual situation in the populations of the Japanese mainland.

In conclusion, it may be said that some number of chromosome $\mathrm{III}^{\mathrm{M}}$ including the $6 P G D^{I}$ allele recently immigrated into the Sapporo population from the south.

We thank Drs. T. Hiroyoshi, H. Inoue (Osaka University) and K. Hattori (Hokkaido Institute of Public Health) for providing us with some marker stock or field flies, Drs. T. Mukai (Kyushu University), L. D. Brooks (North Carolina State University) and H. Tachida (National Institute of Genetics) for commenting on the manuscript, and Ms. T. Shimaya for technical assistance. This work was partly supported by a grant (No. 61480141) from the Ministry of Education, Science and Culture of Japan.

\section{REFERENCES}

Franco, M. G., RUbini, P. G. and VeCCHI, M. (1982) Sex-determinants and their distribution in various populations of Msuca domestica L. of Western Europe. Genet. Res. 40, 279-293. 
Green, M. M. (1980) Transposable elements in Drosophila and other Diptera. Ann. Rev. Genet. $14,109-120$.

HIROYOSHI, T. (1964) Sex-limited inheritance and abnormal sex ratio in strains of the housefly. Genetics 50, 373-385.

HIRoноSHI, T. (1977) Some new mutants and revised linkage maps of the housefly. Musca domestica L. Jpn. J. Genet. 52, 275-288.

HIRoYoshi, T. and FuxUMORI, Y. (1977) On the III $^{\mathrm{M}}$-type houseflies frequenctly appeared in Japan. $J p n$. J. Genet. 52, 443 (in Japanese).

HIRoHoSHI, T. and IoUE, H. (1979) On the IM-chromosome of the housefly. Jpm. J. Genet. 54, 434 (in Japanese).

INOUE, H., FuKUMORI, Y. and HiRoyoshi, T. (1983) Mapping of autosomal male-determining factors of the housefly, Musca domestica L., by means of sex-reversal. Jpn. J. Genet. 58, 451-461.

INoUe, H. and HIROYOSHI, T. (1984) Mapping of autosomal male-determining factors of the housefly, Musca domestica L., by using a female-determining factor. Jpn. J. Genet. 59, 453-464.

InOUe, H., Tomita, T. and HiRoyoshi, T. (1986) Location of fourth chromosomal mele-determining factors of the housefly, Musca domestica. Jpm. J. Genet. 61, 119-126.

Malacrida, A., Gasperi, G. and Milani, R. (1982) 6PGD in the housefly: Mapping of the 6PGD locus in linkage group III of Musca domestica. J. Heredity 73, 349-352.

McDonald, I. C., Overland, D. E., Leopold, R. A., Degrugillier, M. E., Morgan, P. B. and Hofmann, H. C. (1975) Genetics of housefly: Variability studies with North Dakota, Texas, and Florida populations. J. Heredity 66, 137-140.

NEI, M. and LI, W.-H. (1980) Non-random association between electromorphs and inversion chromosomes in finite populations. Genet. Res. 35, 65-83.

Rubini, P. G. and Palenzona, D. (1967) Response to selection for high number of heterochromosomes in Musca domestica L. Genet. Res. 21, 101-110.

ShoNo, T., HoRIo, M. and Tsukamoto, M. (1982) Male-determining systems in natural populations of the housefly in Hokkaido, Japan. Jpn. J. Sanit. Zool. 33, 281 (in Japanese).

Stone, W. S., Johnson, F. M., KoJma, K. and WheEler, M. R. (1968) Isozyme variation in island populations of Drosophila. I. An analysis of a species of the nasta in Samoa and Fiji. Univ. of Texas Publ. 6818, 157-170.

Sullivan, R. L. (1958) Sex limitation of several loci in the housefly. Proc. 10th Intern. Congr. Genet. 2, 282.

Tomita, T. and WADA, Y. (1989) Multifactorial sex determination in natural populations of the housefly (Musca domestica) in Japan. Jpn. J. Genet. 64, 373-382.

Tsukamoto, M., Shono, T. and Horio, M. (1980) Autosomal sex-determining system of the housefly: Discovery of the first-chromosomal male factor in Kitakyushu, Japan. J. Univ. Occupational and Environmental Health 2, 235-252.

WAGONER,. D. R. (1969) Presence of male determining factor found on three autosomes in the housefly, Musca domestica. Nature 233, 187-188. 